\title{
Prevalence of congenital heart defects in patients with Down syndrome in the municipality of Pelotas, Brazil
}

\author{
Luciana T. Vilas Boas, ${ }^{1}$ Elaine P. Albernaz, ${ }^{2}$ Rafaéla Gonçalves Costa $^{3}$
}

\begin{abstract}
Objective: To determine the prevalence of congenital heart defects in patients with of Down syndrome in the municipality of Pelotas, Brazil, describing the most frequent types and assessing the associated factors.

Methods: Cross-sectional study including children with Down syndrome who were born and lived in Pelotas from January 2000 to December 2005. Data were collected by means of home interviews with mothers or guardians. Univariate and bivariate analyses were carried out to analyze the factors related to congenital heart defect.

Results: Forty-seven mothers of patients with Down syndrome were interviewed. Twenty-two (46.8\%) of the patients had a diagnosis of congenital heart defect. Of them, $28 \%$ had early cardiac evaluation before 3 months of life. The most frequent heart defect was interatrial communication (17\%); atrioventricular septal defect affected five patients. Bivariate analysis between the outcome congenital heart defect and the predicting factors maternal age, paternal age, parents' and child's skin color, presence of other malformations and child's sex showed that the associations were not statistically significant.

Conclusions: The prevalence of Down syndrome and congenital heart defects in our region is similar to the rates found by other authors; therefore, we highlight the importance of diagnostic suspicion and early referral by pediatricians to cardiac evaluation. Another relevant aspect is the small number of patients who underwent karyotype testing. In addition, the number of associated malformations was lower than that found by other authors.
\end{abstract}

J Pediatr (Rio J). 2009;85(5):403-407: Down syndrome, congenital hear defect, prevalence.

\section{Introduction}

During the last few years, Down syndrome has been the focus of special attention, mainly due the fact that it is the most frequent chromosome abnormality among newborns. ${ }^{1,2}$ Its incidence in the general population is approximately 1 per 600 to 1,000 births, but this rate may vary according to maternal age. In mothers older than 45 years old, ${ }^{3}$ the syndrome can reach an incidence of 1 per 30 births.

The diagnosis is basically established based on the patient's phenotype, being later confirmed by the karyotype.
Approximately $95 \%$ of the carriers of Down syndrome have primary trisomy; the remaining have the translocation (5\%) or mosaic ( 2 to $3 \%)^{4}$ type, and the recurrence risk in the general population is $1 \% .1,2$

Most patients have generalized hypotonia and neuropsychomotor development delay. The occurrence of the following several isolated or associated malformations is possible: alterations in the thyroid, gastrointestinal tract, bones, eyes and blood. 5

1. Mestranda, Saúde e Comportamento, Universidade Católica de Pelotas (UCPel), Pelotas, RS, Brazil.

2. Doutora, Epidemiologia, Universidade Federal de Pelotas (UFPel), Pelotas, RS, Brazil. Professora adjunta, Programa de Pós-Graduação em Saúde e Comportamento, UCPel, Pelotas, RS, Brazil.

3. Acadêmica de Medicina, UCPel, Pelotas, RS, Brazil.

This study was conducted at the Life and Health Sciences Center, Universidade Católica de Pelotas (UCPel), Pelotas, RS, Brazil.

No conflicts of interest declared concerning the publication of this article.

Suggested citation: Vilas Boas LT, Albernaz EP, Costa RG. Prevalence of congenital heart defects in patients with Down syndrome in the municipality of Pelotas, Brazil. J Pediatr (Rio J). 2009;85(5):403-407.

Manuscript submitted May 8 2009, accepted for publication Jul 12009.

doi:10.2223/JPED.1934 
Although many of the malformations mentioned may define these children's clinical course, congenital heart defects are conditions that have a direct influence on both the patients' prognosis and survival, ${ }^{6}$ being the highest cause of morbidity and mortality during the first 2 years of life. ${ }^{7-9}$ Freeman et al., in a population-based study, analyzed the relationship between presence of congenital heart defect and maternal age, but they did not find an association between both variables. ${ }^{10}$

The prevalence of congenital heart abnormalities in patients with Down syndrome ranges from 40 to $50 \% .7,8$ Among the patients who have a congenital heart defect, half of them presents with atrioventricular septal defect (AVSD), which is rarely an isolated heart defect (2.8\%).7,9 In a 10-year follow-up study about AVSD, the authors found high mortality rate when AVSD was related to Down syndrome. ${ }^{11}$

In addition to AVSD, interatrial communication (IAC), interventricular communication (IVC) and patent ductus arteriosus (PDA) are also frequent in Down syndrome. These pathologies are associated with lower mortality rates and less complications. ${ }^{7}$ There is great controversy in the literature with regard to the most prevalent heart defect in Down syndrome: some authors mention the AVSD,7,11-13 while others mention the IVC. ${ }^{14}$

In a study conducted in Brazil, Granzotti et al. found the presence of a significant number of children with tetralogy of Fallot, which is seldom associated with Down syndrome. ${ }^{2}$ On the other hand, other studies have shown low incidence of this disease in Down syndrome patients.9,10

During the last few years, there has been a significant increase in the life expectancy of patients with Down syndrome who have heart defects both due to early diagnosis and effective surgical treatments. It certainly requires better clinical training of the professionals that provide care to these children and adequate support from the health system. ${ }^{10}$

There are reports of high mortality rate during these patients' first year of life in the literature. ${ }^{15}$ CalderonColmenero et al., in a retrospective study, showed the importance of an early clinical diagnosis and the consequent surgical correction ${ }^{16}$ : when heart defects had early surgical correction, patients had better survival in comparison with those who did not undergo surgical correction.9,11,16

Data from the literature validate the fact that carriers of Down syndrome may present early structural lung abnormalities (alterations in the pulmonary microvasculature $)^{17}$ followed by pulmonary hypertension. In case of a congenital heart defect with left-to-right shunt, there would be higher intrapulmonary flow, thus worsening hypertension and leading to permanent pulmonary hypertension (Eisenmenger's syndrome), which is irreversible and incompatible with life. ${ }^{18,19}$
With regard to the risk factors associated with mortality, several studies have defined that congenital heart defects are the most prevalent risk factors, followed by abnormalities in the digestive tract and leukemia. 8,9,20 The later the surgical indication for congenital heart defect is proposed, the worse will be the child's prognosis. ${ }^{21-23}$

In Brazil, there are few data about congenital heart defects in patients with Down syndrome, 8,24 which is a highly prevalent situation, since several patients seek medical care when it is too late, making it impossible to perform surgical correction and, as a result, increasing morbidity and mortality. $7,15,25,26$

The objective of the present study was to identify the prevalence of congenital heart defects in patients with Down syndrome in the municipality of Pelotas, Brazil, describing the most frequent types and assessing the associated factors.

\section{Methods}

A cross-sectional study that identified patients using the database of children who were born with congenital malformation in the municipality of Pelotas, Brazil, the records of echocardiograms from heart disease clinics, the records of patients seen at the outpatient clinics of pediatric cardiology of Universidade Federal de Pelotas and Hospital Beneficiência Portuguesa de Pelotas and also the records from the following centers and associations that provide care to children with special needs: Rehab Center of Pelotas (Centro de Reabilitação de Pelotas, CERENEPE), Information System of Live Births (Sistema de Informação de Nascidos Vivos, SINASC), Association of Parents and Friends of Special Need Individuals (Associação de Pais e Amigos dos Excepcionais, APAE) and Association of Relatives and Friends of Carriers of Down Syndrome (Associação dos Familiares e Amigos do Down, AFAD). These were the sources of data researched in the municipality of Pelotas.

The sample was estimated based on the number of births in Pelotas: approximately 4,800 births/year, and around eight patients/year, making up a total of 48 (0.1$0.2 \%$ ) children with Down syndrome. All patients with Down syndrome who were born and lived in Pelotas from January 2000 and December 2005 and who had received a clinical diagnosis or karyotype test with positive result for Down syndrome were included in the sample. All patients who had an echocardiogram or surgical description of congenital heart defect defining the diagnosis were considered carriers of congenital heart defects.

Data collection was performed by means of a structured, precodified questionnaire, which was administered to mothers during a home visit, between January 2006 and January 2007. Quality control was carried out using a pretest of the questionnaires, an instruction manual, a revision of 
the questionnaires, as well as a second visit to a random sample of $10 \%$ of the population, with administration of the brief version of the questionnaire to assess the quality and veracity of the data collected.

Double entering of data was performed using the EpiInfo version 6.02. The Statistical Package for the Social Sciences (SPSS) for Windows, version 10.0, was used for data analysis. We calculated the frequencies of variables and the bivariate analysis between the outcome (congenital heart defect) and predicting factors (sex, skin color, family income, and educational (evel). The associations with $p$ values $<0.05$ were considered statistically significant.

The present project was approved by the Research Ethics Committee of Santa Casa de Misericórdia de Pelotas and Universidade Católica de Pelotas. Mothers signed an informed consent form regarding the interviews. Patients who had not had a cardiac investigation were referred to the Outpatient Clinic of Pediatric Cardiology of Universidade Federal de Pelotas in order to be evaluated, with no medical expenses for the family.

\section{Results}

Between January 2006 and January 2007, we interviewed 47 mothers/relatives of children with Down syndrome who were born and lived in Pelotas. Of them, $48.9 \%$ were males and $87.2 \%$ were white. With regard to the parents' skin color, $82.5 \%$ were white. The sample distribution according to socioeconomic and demographic characteristics is shown in Table 1 . Most parents had 5 years or more of schooling, and their family income was lower or equal to three minimum salaries. In terms of maternal age during the patient's gestation period, we found that $49 \%$ of the mothers were older than 35 years old; in relation to paternal age, we found that most fathers $(57.4 \%)$ were older than 40 years old. Most mothers were multiparas (87.2\%).

Table 2 shows the characteristics of the sample related to the diagnosis of Down syndrome and heart defects. We found that $49 \%$ of the children did not undergo karyotype testing. For those patients who had karyotype testing, trisomy of chromosome 21 was the most frequent alteration (40.4\%). Other associated non-cardiac malformations were found in eight patients (17\%), such as gastroesophageal reflux, hypothyroidism, syndactyly, renal hypoplasia, among others.

The age for evaluation of congenital heart defect was low, since $63.8 \%$ of the patients were evaluated during the first 6 months of age, and most of them had echocardiograms (93.6\%). We also found that all patients had at least one cardiac evaluation during their lives.

The diagnosis of major congenital heart defect was present in $46.8 \%$ of the sample (22 patients), as follows:
$36.3 \%$ of the patients had AVSD, $36.3 \%$ had IAC and $27.4 \%$ had other heart defects (IVC and PDA). Eight patients (36.3\%) had AVSD, five of them had total AVSD and three had partial AVSD. Seven patients could not recall the result of the exam and three did not have an echocardiogram.

Only $2.1 \%$ of the patients received a prenatal diagnosis of Down syndrome. In $83 \%$ of the cases, pediatricians were responsible for referring the patients to cardiac evaluation, and $14.9 \%$ had undergone surgical correction before data collection.

The three patients who did not have an echocardiogram were referred to have it performed; only one of them had the exam, and the result was normal.

We carried out a bivariate analysis between the outcome presence of congenital heart defect and the following predicting factors: maternal age ( $\leq 35$ years and > 35 years), paternal age ( $\leq 35$ years and > 35 years), parents and child's skin color, other malformations, and child's sex. None of the associations was statistically significant.

Table 1 - Sample distribution according to socioeconomic, demographic and reproductive characteristics $(n=47)$

\begin{tabular}{|c|c|c|}
\hline Variable & $\mathbf{n}$ & $\%$ \\
\hline \multicolumn{3}{|c|}{ Family income (minimum wage) } \\
\hline$>6$ & 10 & 21.3 \\
\hline $3,1-6$ & 5 & 10.6 \\
\hline $1,1-3$ & 22 & 46.8 \\
\hline$\leq 1$ & 10 & 21.3 \\
\hline \multicolumn{3}{|c|}{ Mother's educational level (years) } \\
\hline$\geq 12$ & 5 & 10.6 \\
\hline $9-11$ & 12 & 25.5 \\
\hline $5-8$ & 23 & 48.9 \\
\hline $0-4$ & 7 & 14.9 \\
\hline \multicolumn{3}{|c|}{ Father's educational level (years) } \\
\hline$\geq 12$ & 7 & 14.9 \\
\hline $9-11$ & 9 & 19.1 \\
\hline $5-8$ & 21 & 44.7 \\
\hline $0-4$ & 7 & 14.9 \\
\hline Unknown & 3 & 6.4 \\
\hline \multicolumn{3}{|c|}{ Maternal age during pregnancy (years) } \\
\hline$\leq 30$ & 10 & 21.3 \\
\hline $31-35$ & 14 & 29.8 \\
\hline $36-40$ & 13 & 27.7 \\
\hline$\geq 41$ & 10 & 21.3 \\
\hline \multicolumn{3}{|c|}{ Paternal age (years) } \\
\hline$\leq 30$ & 2 & 4.3 \\
\hline $31-35$ & 2 & 4.3 \\
\hline $36-40$ & 15 & 31.9 \\
\hline$\geq 41$ & 27 & 57.4 \\
\hline Unknown & 1 & 2.1 \\
\hline \multicolumn{3}{|l|}{ Parity } \\
\hline Primiparity & 6 & 12.8 \\
\hline Multiparity & 41 & 87.2 \\
\hline Total & 47 & 100 \\
\hline
\end{tabular}


Table 2 - Congenital heart defects in children with Down syndrome $(n=47)$

\begin{tabular}{|c|c|c|}
\hline Variable & $\mathbf{n}$ & $\%$ \\
\hline \multicolumn{3}{|l|}{ Prenatal diagnosis of Down syndrome } \\
\hline Yes & 1 & 2.1 \\
\hline No & 46 & 97.9 \\
\hline \multicolumn{3}{|l|}{ Result of karyotype test } \\
\hline Trisomy & 19 & 40.4 \\
\hline Mosaic Down syndrome & 1 & 2.1 \\
\hline Unknown & 4 & 8.5 \\
\hline Did not have the test & 23 & 48.9 \\
\hline \multicolumn{3}{|l|}{ Associated malformations (non-cardiac) } \\
\hline Present & 8 & 17.0 \\
\hline Absent & 39 & 83.0 \\
\hline \multicolumn{3}{|l|}{ Age at diagnosis (months) } \\
\hline $0-6$ & 30 & 63.8 \\
\hline $7-12$ & 10 & 21.3 \\
\hline $13-18$ & 2 & 4.3 \\
\hline$\geq 19$ & 5 & 10.6 \\
\hline \multicolumn{3}{|l|}{ Echocardiogram } \\
\hline Done & 44 & 93.6 \\
\hline Did not have the exam & 3 & 6.4 \\
\hline \multicolumn{3}{|l|}{ Congenital heart defect } \\
\hline Absent/oval foramen/pulmonary hypertension & 15 & 31.9 \\
\hline Present & 22 & 46.8 \\
\hline Unknown & 10 & 21.3 \\
\hline Total & 47 & 100 \\
\hline
\end{tabular}

\section{Discussion}

Comparing the data from the present study with the literature, ${ }^{1-4}$ we found a prevalence rate of Down syndrome similar to that of the general population ( $8 \%$ ) and a prevalence rate of congenital heart defects similar to other studies in our sample (46.8\%). Among the known congenital heart defects, we found high prevalence of IAC (36.3\%) and AVSD (36.3\%); there was not any case of tetralogy of Fallot, although this disease has been mentioned by other authors. ${ }^{5}$

All children with Down syndrome should have a cardiac evaluation at birth due to the high prevalence of association with heart malformations, which increase mortality during the first year of life. ${ }^{5,7}$ In the present study, a relevant fact is that most patients had echocardiograms (93.6\%), which suggests that an adequate and early cardiac evaluation was performed; age at diagnosis, for most patients, was lower than 12 months of life (85.1\%).

Early clinical diagnosis and consequent surgical correction are extremely important so that a negative evolution regarding the pulmonary function with the development of early pulmonary hypertension can be prevented. ${ }^{8-12}$ In the present study, we found that health care professionals, most of whom were pediatricians, were well trained: most patients were investigated and received a diagnosis during the first year of life.
Old maternal and paternal ages were found for most patients; and half of the mothers and $89 \%$ of the fathers were older than 35 years old during pregnancy. The relation between maternal age and occurrence of chromosome abnormality is well known. However, parental age did not have an influence on the occurrence of congenital heart defects, which is in agreement with other studies. $8,11,12$

We found a low frequency of karyotype testing in the sample: approximately $50 \%$ of the patients did not have the exam even though it plays a confirmatory role in the diagnosis of Down syndrome. Such finding might be explained by the fact that there is great difficulty in Brazil to perform such test maybe due to its high cost. It is also important to highlight the prevalence of associated noncardiac malformations (17\%), which was lower in the present study in comparison with the findings of other authors. $5,8,11$ In spite of being much less frequent than heart defects, these results also deserve to be investigated.

Some authors have emphasized the importance of an early cardiac diagnosis so that the patient can have good postoperative evolution.

Therefore, it is worth mentioning the importance of performing fetal echocardiograms with the purpose of establishing an early diagnosis of several congenital heart defects, in addition to raising the suspicion of Down syndrome and planning the patient's birth in a more adequate manner. $12,16,26$

Although our sample included all patients with Down syndrome who were born in Pelotas during the period covered by the study, our results must be cautiously analyzed because we had a small sample. Nevertheless, due to the lack of national data and the relevance of the topic, the high prevalence of heart defects found in our sample, as well as the findings consistent with other studies, demonstrate the importance of thorough follow-up and investigation of patients with Down syndrome.

\section{Acknowledgements}

The authors thank Dr. Gilberto Garcias for providing the list of patients with Down syndrome included in his study about congenital malformations and the medical students Rafaéla Gonçalves Costa, Priscila Poncelét, Natália Barros, Mariana Frederes and Marina Estrela for their help with data collection.

\section{References}

1. Ferencz C, Neil CA, Boughman JA, Rubin JD, Brenner JI, Perry LW. Congenital cardiovascular malformations associated with chromosome abnormalities: an epidemiologic study. J Pediatr. $1989 ; 114: 79-86$ 
2. Granzotti JA, Paneto IL, Amaral FT, Nunes MA. Incidência de cardiopatias congênitas na Síndrome de Down. J Pediatr (Rio J). 1995;71:28-30.

3. Down JL. Observations on an ethnic classification of idiots. Clinical Lecture Reports. 1866;3:259-62.

4. Jones KL. Smith's recognizable patterns of human malformations. 5th ed. Philadelphia, PA: Saunders; 1997.

5. Beherman RE, Vaughan VC. Nelson textbook of pediatrics. 13th ed. Philadelphia, PA: WB Sanders; 1987.

6. Fabia J, Drolette M. Life tables up to age 10 for mongols with and without congenital heart defects. J Ment Defic Res. $1970 ; 14: 235-42$.

7. Mikkelsen $M$, Poulsen $H$, Nielsen KG. Incidence, survival, and mortality in Down syndrome in Denmark. Am J Genet Suppl. $1990 ; 7: 75-8$.

8. Rodríguez LH, Reyes JN. Cardiopatías congénitas en el síndrome de Down. Bol Med Hosp Infant Mex. 1984;41:622-5.

9. Stoll C, Alembik Y, Dott B, Roth MP. Study of Down syndrome in 238,942 consecutive births. Ann Genet. 1998;41:44-51.

10. Freeman SB, Taft LF, Dooley KJ, Allran K, Sherman SL, Hassold TJ, et al. Population-based study of congenital heart defects in Down syndrome. Am J Med Genet. 1998;80:213-7.

11. Hayes C, Johnson Z, Thornton L, Fogarty J, Lyons R, O'Connor M, et al. Ten-year survival of Down syndrome births. Int J Epidemiol. 1997;26:822-9.

12. Torfs CP, Christianson RE. Anomalies in Down syndrome individuals in a large population-based registry. Am J Med Genet. $1998 ; 77: 431-8$

13. Pinto FF, Nunes L, Ferraz F, Sampayo F. Down's syndrome: different distribution of congenital disease between the sexes. Int ] Cardiol. $1990 ; 27: 175-8$

14. Laursen HB. Congenital heart disease in Down's syndrome. Br Heart J. 1976;38:32-8.

15. Dunlop KA, Mulholland HC, Casey FA, Craig B, Gladstone DJ. A ten year review of atrioventricular septal defects. Cardiol Young. 2004;14:15-23.

16. Calderon-Colmenero J, Flores A, Ramirez S, Patino-Bahena E, Zabal C, Garcia-Montes JA, et al. Results of surgical treatment of congenital heart defects in children with Down's syndrome. Arch Cardiol Mex. 2004;74:39-44.
17. Chi TPL, Krovetz J. The pulmonary vascular bed in children with Down syndrome. J Pediatr. 1975;86:533-8.

18. Shaher RM, Farina MA, Porter IH, Bishop M. Clinical aspects of congenital heart disease in mongolism. Am J Cardiol. 1972;29:497503.

19. Leonard S, Bower C, Petterson B, Leonard H. Survival of infants born with Down's syndrome: 1980-96. Paediatr Perinat Epidemiol. 2000;14:163-71.

20. Källén B, Mastroiacovo P, Robert E. Major congenital malformations in Down syndrome. Am J Med Genet. 1996;65:160-6.

21. Boy R, Neto JG, Vargas FR, Fontana C, Almeida JC, Llerena Jr J. Síndrome de Down - análise clínica, citogenética e epidemiológica de 165 casos. J Pediatr (Rio J). 1995;71:88-92.

22. Lejeune JM, Gautier M, Turpin R. Etudes des chromosomes somatiques de neuf enfants mongoliens. C R Hebd Seances Acad Sci. $1959 ; 248: 602-3$.

23. Polani PE, Briggs JH, Ford CE, Clarke CM, Berg JM. A mongol girl with 46 chromosomes. Lancet. 1960;1:721-4.

24. Clarke CM, Edwards JH, Smallpeice V. 21-Trissomy/normal mosaicism in an intelligent child with some mongoloid characteristic. Lancet. 1961;1:1028-30.

25. Pueschel SM. Clinical aspects of Down syndrome from infancy to adulthood. Am J Med Genet Suppl. 1990;7:52-6.

26. Tandon R, Edwards JE. Cardiac malformations associated with Down's syndrome. Circulation. 1973;47:1349-55.

\section{Correspondence:}

Luciana Thomaz Vilas Boas

Av. Dom Joaquim, 1491/401, Três Vendas

CEP 96020-260 - Pelotas, RS - Brazil

Tel.: +55 (53) 3283.6085, +55 (53) 8114.8894

Fax: +55 (53) 3222.1667

E-mail: Itvb@terra.com.br 